\title{
Eating frequency and weight gain: a prospective analysis using data from the UK Women's Cohort Study
}

\author{
Victoria Burley, Doris Chan and Janet Cade \\ Nutritional Epidemiology Group, Centre for Epidemiology and Biostatistics, University of Leeds, Leeds, UK
}

During the last two decades there has been an alarming increase in the prevalence of overweight and obesity across Europe and North America. Debate continues about the apparent causes of this increase, with much of the blame being apportioned to excessive intakes of dietary fats and/or simple carbohydrates and reduced levels of physical activity. However, the rise in availability of snack foods has also been cited as a potential contributor to the prevalence of obesity ${ }^{(1)}$. Within the scientific literature, however, existing evidence is unclear as to the direction of the effect of snacking behaviour on body-weight status.

In the present study a prospective investigation of the effects of eating pattern on body-weight change in the UK Women's Cohort Study (UKWCS) was undertaken. The UKWCS is a 10-year prospective investigation of the relationship between diet and cancer in middle-aged women across the UK. Full details of the cohort participants have been published elsewhere ${ }^{(2)}$. Using eating frequency and body-weight status as recorded in 1999-2000 and a 6-year follow-up 1929 women, initially aged 55 years on average (range 37-77 years), were included in a logistic regression analysis that assessed the association between change in body weight and eating pattern. The number of eating events per $\mathrm{d}$ was captured from $4 \mathrm{~d}$ semi-weighed food diaries, and body weights were obtained by self report. Each eating event was defined as any energetic solid, semi-solid or liquid food or drink that was separated from the next event by $\geq 15$ min.

Table. Baseline and selected changes in characteristics according to weight change status

\begin{tabular}{|c|c|c|c|c|c|c|c|c|}
\hline \multirow[b]{2}{*}{ Variable } & \multicolumn{2}{|c|}{ Weight gainers } & \multicolumn{2}{|c|}{ Weight maintainers } & \multicolumn{2}{|c|}{ Weight losers } & \multicolumn{2}{|c|}{ Statistical significance } \\
\hline & Mean & $\mathrm{SD}$ & Mean & $\mathrm{SD}$ & Mean & SD & $\mathrm{F}$ & $P$ \\
\hline$n$ & \multicolumn{2}{|c|}{651} & \multicolumn{2}{|c|}{854} & \multicolumn{2}{|c|}{424} & & \\
\hline Age (years) & 53.3 & 7.6 & 55.6 & 8.6 & 57.9 & 8.5 & 41.7 & $<0.001$ \\
\hline Weight (kg) & 65.4 & 11.4 & 62.5 & 9.9 & 67.8 & 13.2 & 39.2 & $<0.001$ \\
\hline Weight change (kg) & 5.62 & 3.7 & 0.06 & 1.1 & -5.61 & 3.9 & 1946.7 & $<0.001$ \\
\hline $\operatorname{BMI}\left(\mathrm{k} / \mathrm{m}^{2}\right)$ & 24.4 & 4.1 & 23.2 & 3.6 & 25.3 & 4.6 & 40.8 & $<0.001$ \\
\hline $\begin{array}{l}\text { Eating frequency (no. of } \\
\text { times per d) }\end{array}$ & 7.9 & 1.2 & 7.9 & 2.1 & 7.5 & 1.9 & 4.3 & 0.013 \\
\hline
\end{tabular}

On average the women experienced a small increase in body weight $(+0.71$ (SD 4.9) $\mathrm{kg}$ ) during the follow-up period, but within this small change there was considerable variation. More than one-third of the women gained $>2.2 \mathrm{~kg}$ (weight gainers), $22 \%$ had lost $\geq 2.2 \mathrm{~kg}$ (weight losers) and $44 \%$ had maintained their weight within $2.2 \mathrm{~kg}$ (weight maintainers) (see Table). As a result of concerns about the intentionality of the weight loss in the weight losers, the analysis was focused on the risk of weight gain relative to weight maintenance. In a model that adjusted for a range of confounders, the odds of weight gain rather than maintenance decreased with age $(P<0.001)$, increased with initial BMI $(P<0.001)$ and were higher in women who had reduced their activity level $(P=0.002)$. Eating frequency $($ total eating or drinking events) was associated with a reduced odds of weight gain in women $<60$ years of age only (for each unit increase, OR 0.95 (95\% CI $0.89,1.00) ; P=0.057)$, but not in the whole sample of women. While causality may not be inferred from these observational data, the results of these analyses indicate that more-frequent eating and drinking was not associated with greater weight gain in middleaged women.

This study was supported by the World Cancer Research Fund.

1. Berteus FH, Torgerson JS, Sjostrom L \& Lindroos AK (2005) Int J Obes (Lond) 29, 711-719.

2. Cade JE, Burley VJ, Greenwood D \& UKWCS Steering Group (2004) Public Health Nutr 7, 871-878. 